\title{
El liberalismo hispanoamericano en el siglo XIX
}

Mario A. Pozas

Doctorado en Filosofía Iberoamericana

UCA, San Salvador

RESUMEN: El pensamiento bispanoamericano ba solido nutrirse de la apropiación creativa de ideas de otras latitudes. El caso del liberalismo decimonónico es paradigmático a este respecto, pues presenta unas características muy propias, que no sólo la diferencian del liberalismo europeo en términos filosóficos, sino que también la constituyeron en una corriente que influyó en la vida institucional latinoamericana.
ABSTRACT: Hispanic American thought bas nourished itself from a creative appropriation of ideas from other latitudes. The case of Liberalism on $19^{\text {th }}$ century is paradigmatic. Latin American Liberalism bad very singular features that differentiate it from European Liberalism, not only in philosophical terms, but also turned it in a very influencing paradigm in the Latin American institutional life.

Después de una larga disputa sobre la historia e identidad del pensamiento filosófico hispanoamericano, es necesario reconocer, en primer lugar, que éste ha surgido dentro de los confines y en el contexto una cultura específica, es decir, la europea occidental, expresada particularmente por España y Portugal. En segundo lugar, este pensamiento ha sido la manifestación de una sociedad elitista, fuertemente estratificada, donde han sido los intelectuales y políticos quienes han recibido las influencias de las distintas corrientes y han formulado su propia lectura, a partir de su específica realidad americana (Bethel, 1).

Ef liberalismo hispanoamericano en el siglo XIX 
Como lo expresa Leopoldo Zea: "el latinoamericano se ha servido de ideas que le eran relativamente ajenas para enfrentarse a su realidad: la ilustración, el eclecticismo, el liberalismo, el positivismo y, en los últimos años, el marxismo, el historicismo y el existencialismo. En cada uno de estos casos, ... ha estado en la mente del latinoamericano la idea central de hacer de su América un mundo a la altura del llamado mundo occidental" (El pensamiento latinoamericano).

En este sentido, el liberalismo se configuró en la región, como una corriente aglutinadora que sentó las bases e inspiró, en un primer momento, a los movimientos independentistas y, posteriormente, a los programas y teorías que sirvieron para la instauración y consolidación de los gobiernos, así como para la reorganización social, necesaria con posterioridad al desquebrajamiento del orden colonial (Bethel, 2).

Sin embargo, como se verá más adelante, si bien la independencia fue una gesta con aspiraciones libertarias, no por ello dejó de ser un movimiento oficialista y superficial, alejado de los verdaderos intereses de las mayorías, ni logró superar esa dramática realidad de una dependencia más profunda y significativa en que se encontraban los pueblos americanos, es decir, la dependencia mental.

Esta dependencia de carácter cultural, internalizada en el ser americano, impidió que el afán por hacer de estos países, naciones organizadas, democrática y liberalmente, se concretara. La adopción de técnicas modernas de convivencia, implicaba la renuncia a un pasado - reflejado en el catolicismo y la escolástica- el cual seguía tan vivo y presente como antes de la Independencia, por lo que se conservaron las formas despóticas de poder, una sociedad estamental y la pervivencia de grupos privilegiados (cfr. Bethel, 29-30).

Lo anterior, aunado a la ligazón con Europa y los intereses económicos del naciente sistema capitalista internacional, condicionaron el desarrollo de los países latinoamericanos en los cincuenta años posteriores a la Independencia, configurándolos como meras economías agroexportadoras, proveedoras de materias primas para la creciente actividad industrial del Viejo Continente (Bethel 1).

Por ello es que este sistema, reflejado en el liberalismo, entró nuevamente en crisis, pues "la violencia era la forma de sucesión de los gobernantes en Hispanoamérica. A éstos no preocupa ya otra cosa que mantenerse en el poder, por el poder. A nadie parecía importarle ya el 
futuro de las sociedades hispanoamericanas, lo único que parecía importar era la forma de ocupar el lugar de mando, dejado por el anterior gobernante" (Zea, 68).

En todo caso, el liberalismo catapultó a las sociedades latinoamericanas de las postrimerías del siglo XIX al sistema económico mundial, basados en el principio de la libre empresa individual, mediante la instauración de un sistema de instituciones republicanas, constitucionales y representativas, con regímenes de derecho, que superaron el oscurantismo de la sociedad colonial y dan paso a modernos criterios seculares en la educación y la organización civil, así como al surgimiento de los modernos centros urbanos y cosmopolitas.

Desde esta perspectiva, el liberalismo se convierte en un mito unificador contra el orden colonial y constituye la emancipación espiritual de América.

Como veremos, el liberalismo enfrentó sus propias contradicciones, para dar paso a nuevas formas de pensamiento latinoamericano, como será el positivismo, el marxismo, el socialismo y la filosofía de la liberación.

\section{Aproximación a la noción de liberalismo hispanoamericano}

Así como el tránsito de la filosofía latinoamericana del siglo XVIII al XIX estuvo marcado por la pugna entre la escolástica y el positivismo, así también el conservadurismo y el liberalismo constituyeron las ideologías que agruparon a los distintos movimientos políticos y sociales de ese mismo período.

Ahora bien, esta interacción entre filosofía, política y economía que suele denominarse como liberalismo, ha sido múltiple y diversa, al mismo tiempo que muchas otras doctrinas han ido identificándose con esta corriente de pensamiento: individualismo, racionalismo, universalismo o utilitarismo. Por otra parte, no es menos cierto que al ubicarse dentro de los "ismos", el pensamiento liberal ha adoptado una connotación ideológica, en el sentido de pretender constituir "una doctrina articulada que comprende una visión general del mundo, a partir de la cual se construyen modelos teóricos que pretenden interpretar la realidad, y un cierto modelo prescriptivo, desde donde se señalan ciertas opciones de valor y se enmarcan criterios relacionados con el deber ser o con la posibilidad de un cierto modo de ser del mundo" (Michelangelo Bóvero, citado por Yturbe, 15). 
Aunque sea difícil catalogar a las distintas vertientes del liberalismo e incluso hayan profundas diferencias entre los fundamentos de unas y otras, lo cierto es que su denominador común se encuentra, por un lado, en su noción del ser humano como un ser libre y, por el otro, en su teoría de la limitación del poder público del Estado, las cuales en conjunto dieron lugar a la búsqueda de garantías, por medio de las distintas Cartas o Declaraciones, más o menos eficaces que se han dictado en el transcurso de la historia.

En el mismo sentido, en Hispanoamérica el liberalismo no siempre mantuvo una sola identidad, sino más bien se trató de una corriente que agrupó una diversidad de tendencias históricas, que algunos identifican más bien como un "conglomerado liberal" (Biagini, citado por Acosta, 343).

\section{Características del liberalismo hispanoamericano}

El liberalismo hispanoamericano mantuvo rasgos propios, que a pesar de las profundas diferencias entre sus cultivadores y de las distintas realidades a las que se aplicó, permiten diferenciarlo de otras corrientes filosóficas. Entre sus notas específicas se encuentra su individualismo, igualitarismo, universalismo y meliorismo.

Asimismo, la actitud liberal encarna una preeminencia de las virtudes de la razón, la creencia en el orden como fuente de bienestar y una confianza en el progreso ilimitado de la humanidad.

Sin embargo, las características políticas más importantes y que modificaron la semblanza institucional del continente radican en su republicanismo, constitucionalismo, secularismo y en su aspiración hacia la unidad hispanoamericana, como se verá a continuación.

\subsection{Republicanismo}

Frente al Viejo Mundo, los americanos liberales ondeaban la bandera del republicanismo. Así, pues, en el centro del espíritu del Nuevo Mundo, que inspira a sus instituciones libres y las esperanzas del nuevo hombre, se hallaba la República.

La República, entendida como una forma de limitar el poder absoluto, así como una distribución de funciones y competencias, con un conjunto de pesos y contrapesos, que pusiera fin a las formas despóticas del ejercicio del poder, era un rasgo que enfrentaba a los liberales con los conservadores. 
Lastarria y Bilbao son el ejemplo de la ruptura con la mentalidad feudal de España y en la apuesta a nuevas formas republicanas de organización política.

Incluso, Lastarria llega a sostener que la idea de una raza latina en Europa y América era sólo una idea napoleónica, cuya finalidad estribaba en restaurar el absolutismo en el Nuevo Mundo, imputándoles a los descendientes latinos la incapacidad de gobernarse por otras formas políticas.

\subsection{Constitucionalismo}

Se ha llegado a sostener que "un elemento significativo de la herencia liberal de América Latina era el entusiasmo por los sistemas constitucionales... entendido básicamente como un código de leyes escritas y concebidas racionalmente para distribuir el poder político de manera eficaz y garantizar la libertad individual" (Bethel, 6)

El constitucionalismo liberal tiene por finalidad primordial limitar la autoridad por medio de la instauración de barreras jurídicas contra el "despotismo" que se asociaba al régimen colonial.

La noción de este constitucionalismo tiene su fuente en la Ilustración, específicamente en la teoría de los derechos naturales del hombre, por un lado, y en el utilitarismo, por el otro, las cuales si bien son doctrinas opuestas entre sí, ambas reconocían el valor del individuo como ente autónomo.

Posteriormente, esta noción del derecho como sinónimo de legalismo, fue abandonada por considerarse abstracta y de discutible aplicación universal, por lo que se renuncia al constitucionalismo clásico, a partir de las ideas de Savigny relativas al método comparativo e histórico del derecho. Así, Alberdi consideró que el derecho no debía considerarse como una colección de leyes escritas, sino como un elemento vivo y continuamente progresivo de la vida social.

Uno de los problemas más importantes a los que hubo de prestar atención desde la perspectiva constitucional, es el relativo a la organización territorial del Estado. Así, se dio un enfrentamiento entre la tradición unitaria versus una federalista que pretendía atender los intereses regionales. Al final, los derroteros adoptados por los países hispanoamericanos fueron diversos, coexistiendo distintas alternativas a la fecha.

297

El Ilberalismo hispanoamericano en el siglo XIX 


\subsection{Supremacía del estado secular}

Este aspecto era, sin lugar a dudas, uno de los elementos diferenciadores más importantes entre los liberales y conservadores de la época.

Para los liberales, el Estado moderno, formado por individuos libres, iguales ante la ley y sin restricciones en la búsqueda de su propio interés ilustrado, debía ser un Estado secular. De tal suerte que como ciudadanos su lealtad era a la nación y la ley, no a la iglesia u otros entes corporativos coloniales.

Propusieron los liberales que las estadísticas vitales, los procesos fiscales, el procedimiento judicial, la educación, el calendario, los nacimientos, bodas y defunciones, debían apartarse del control de la iglesia (Bethel, 10).

Otro punto que dividió profundamente a la sociedad hispanoamericana, tenía que ver con la riqueza eclesiástica (diezmos, bienes raíces, hipotecas), la cual desde la perspectiva liberal debía pasar de la mano muerta de la iglesia y convertirse en estímulo de la empresa individual.

A tal grado fue el conflicto entre liberales y conservadores en materia de secularismo que provocó la guerra civil de México, entre los años 1854 a 1867 (Bethel, 10).

Por otra parte, en la misma medida que aumentaba la oposición conservadora, aumentaban las exigencias del programa liberal.

En Colombia, por ejemplo, el liberalismo estuvo representada por "los radicales", un grupo de pensadores y políticos que favorecía el impulso de la enseñanza secularizada, la separación entre iglesia y estado, el federalismo republicano y la no intervención estatal.

\subsection{Aspiración hacia la unidad hispanoamericana}

Aunque algunos conservadores, tales como Lucas Alamán o Diego Portales, se mostraron favorables a la unidad del continente con posterioridad al momento independentista, lo cierto es que pronto abdicaron de sus aspiraciones hispanoamericanistas e incluso en algunos casos extremos, como los del conservadurismo mexicano, llegaron a favorecer la intervención de potencias extrañas, como fue el caso de la invasión francesa a México (Santana, 34).

Por ello, es más bien el liberalismo donde se encuentran los mayores esfuerzos por la unidad latinoamericana, especialmente en su tendencia 
democrática liberal y burgués-urbana de las emergentes clases medias, que retoma los ideales bolivarianos. Este es el caso de Francisco Morazán y su lucha por unidad en Centroamérica o el latinoamericanismo propuesto por el argentino Juan Bautista Alberdi (Santana, 34).

\section{Antecedentes del liberalismo hispanoamericano}

Es emblemático que, la primera vez que se utilizó el término "liberal", como adjetivación política, es en el marco del nacimiento de las Cortes de Cádiz en 1811, las cuales suponían un planteamiento de tipo contractualista entre el rey y los súbditos, que implicaba, a su vez, que la soberanía había retrovertido en el pueblo.

Sin embargo, la Constitución de 1812 no satisfizo las exigencias de libertad e igualdad a que aspiraban los criollos dominantes, pues sin independencia estaban convencidos que se mantendrían las causas de la desigualdad.

En todo caso, el surgimiento del liberalismo se asocia, al igual que en Europa, con el aparecimiento de nuevas clases sociales, es decir, distintas a las coloniales.

Con el objeto de analizar las influencias para la formación de la conciencia política liberal y republicana en Centroamérica, puede acudirse a los archivos de la Inquisición de Guatemala. Así, es posible confirmar que autores como Juan Jacobo Rousseau, el abate Pradt, el Barón de Montesquieu, Voltaire, Paine, Hume y Jeremías Benthan, eran leídos y conocidos en la región, a la vez que doctrinas tales como las del pacto social, la soberanía popular, la división de poderes, los derechos naturales, el poder constituyente y la teoría de la representatividad estaban difundidas entre los intelectuales y políticos de la época pre-independentista (García Laguardia, 11).

Incluso, se destaca que " $E l$ Contrato Social", cuya primera traducción se hace en 1779, por exilidados españoles en Londres, es conocido en Guatemala cuatro años más tarde, a pesar de los problemas de distancia, transportación y represión eclesiástica. Por otra parte, es destacable el intercambio epistolar entre Bentham y el prócer centroamericano José Cecilio del Valle.

Ahora bien, el liberalismo como corriente de pensamiento surge en la Edad Moderna y sus orígenes es posible ubicarlos en Inglaterra durante los siglos XVII y XVIII, a partir de la revolución de 1688 contra Jacobo II. 
Su expresión clásica recae en las obras de John Locke y los ejes de su filosofía política se encuentran en el constitucionalismo, la tolerancia religiosa y la construcción de una sociedad de mercado.

Por otra parte, el liberalismo también ha tenido su influjo jurídico, que "al sustentarse en el principio de la soberanía popular y en la garantía del bienestar individual... motivó [en Hispanoamérica] la búsqueda en el extranjero de materiales de construcción que ayudaran a levantar la nueva nación sobre las bases que proporcionaba un régimen político que había sido implantado ya en otros países... eso explica la ininterrumpida serie de traducciones y reediciones en español de clásicos europeos del pensamiento liberal, y de comentaristas y divulgadores de sus doctrinas, que se acometió entre 1820 y 1825" (Ferrer, 3).

Los hispanoamericanos adoptaron de cada autor aquello que pudiera contribuir a su causa independentista o reguladora del nuevo orden postcolonial.

Para el caso, de Locke se extrae la noción de inseparabilidad entre libertad y propiedad privada como expresión central de los derechos naturales y el consentimiento individual, periódico y condicional, como fuente de legitimidad; de Paine, el énfasis en la soberanía popular y el anti-absolutismo; de Rousseau, el democratismo y republicanismo con su visión positiva de la libertad que parece realizarse a través del Estado, a diferencia de Locke que sustenta una visión negativa de la libertad, entendida como ausencia de coacciones gubernativas, en la que se funda la tesis del Estado Mínimo; de Montesquieu, la división de poderes; de Voltaire, su registro del meliorismo que fundamenta el sentido del progreso y perfectibilidad humana; $y$, del constitucionalismo norteamericano, influyen dos principios que no se habían presentado antes conjuntamente, ni en forma apropiada en otros modelos históricos, es decir, el republicanismo y el federalismo.

Todas estas ideas, le dieron identidad al movimiento liberal hispanoamericano, mezclado con las relaciones y sentimientos ambiguos de los criollos hacia su herencia española.

Ahora bien, no se haría suficiente justicia, sino se reconociera entre las raíces del liberalismo hispanoamericano, los aportes de los filósofos humanistas novohispanos (Beuchot), tales como Fray Juan de Zumárraga (1468-1548), Don Vasco de Quiroga (1480-1565), Fray Alonso de la Vera Cruz (1507) o el prominente defensor de los indios Bartolomé 
de las Casas. Esos autores, desde y durante la época de la Conquista, defendieron la humanidad de los indios y sus derechos como personas, se opusieron a la esclavitud y a otras formas de opresión, tales como las encomiendas o los repartimientos (Pérez).

La lista de pensadores liberales hispanoamericanos es dilatada y se encuentran en todos y cada uno de los países de la región, con sus particularidades y expresiones propias.

Destacan, especialmente, intelectuales de la talla de:

Fray Servando Teresa de Mier (México, 1763-1827): Representante del "protoliberalismo" americano, comienza a utilizar el término "nación" como el origen y fundamento de la soberanía, acorde con sus aspiraciones independentistas no democráticas. Su obra más memorable es el discurso sobre la federación mexicana, ante el Congreso Constituyente de 1823, en el que aborda el problema del federalismo y el centralismo, inclinándose por lo que denominó un "federalismo moderado".

José Cecilio del Valle (Honduras, 1780-1834): participó activamente en los movimientos independentistas de México y Centroamérica. Su pensamiento está influido por la Economía Política, por lo cual más que centrarse en la independencia, visualizaba ya la revolución liberal y las transformaciones que esto significaba para la región. Consideraba al trabajo como la primera virtud civil de un ciudadano, pero en consonancia con Locke, el valor del trabajo se ve desplazado por la propiedad, por lo cual los propietarios eran el cuerpo y alma de la nación.

Juan Bautista Alberdi (Argentina, 1810-1884): representa el liberalismo en su articulación con los problemas de los Estados independientes.

Representantes de las distintas tendencias liberales son: Andrés Bello (Venezuela, 1781-1865), liberalismo conservador; José Victorino Lastarria (1817-1888), liberalismo moderado, y; Francisco Bilbao (18231865): liberalismo radical.

Pero todos estos americanos tenían en común que entendían la libertad como sinónimo de independencia, no en abstracto, sino como referido a la península Ibérica, a la vez que la igualdad, se asumía como la superación de los privilegios establecidos durante el orden colonial. 
Un breve recuento histórico, nos permite determinar que en Hispanoamérica, para 1810, la Colonia estaba ya claramente dividida en dos grupos: los realistas o conservadores, que se mantenían fieles a la Monarquía; $y$, los patriotas o liberales que buscaban decididamente la independencia (Gómez).

En adelante, de los años de 1820 hasta 1870, hubo constantes conflictos ideológicos, por lo que se trató de un período de confusión política y de modificaciones a las doctrinas clásicas del liberalismo, para ambientarlas a la realidad hispanoamericana (Bethel, 2).

Es hasta los años de 1870 a 1890 que se puede hablar de una verdadera realización del liberalismo hispanoamericano.

No obstante, ya en los albores del siglo XX, se comienza a advertir el fracaso del primer intento liberal en Centroamérica, debido a la falta de una estructura económica estable e importante, la falta de centros urbanos modernos y la creciente exclusión de las mayorías sociales.

Como sostiene García Laguadia: "En general, los gobiernos liberales que se implantan en Latinoamérica después de la independencia tuvieron que devenir en gobiernos fuertes. Su necesidad, tan contraria al espíritu liberal doctrinario, tiene su origen en el hecho, de que un estado gendarme en el sentido teórico, sólo podía existir allí donde ya hubiese sociedad liberal en tanto que a un gobierno liberal en una sociedad con fuertes resabios coloniales, sólo le cabía tomar una actitud enérgica en política e intervensionista en la economía" (García, 35)

\section{Roles del liberalismo en Hispanoamérica}

En este específico contexto histórico, el liberalismo hispanoamericano asume roles claramente delimitados, aunque no por ello, contradictorios recíprocamente. Así, es posible identificar dos funciones, según se trate durante la etapa de la Independencia o la etapa de consolidación de los nuevos Estados independientes.

En un principio, el liberalismo conformó una ideología funcional para las aspiraciones de ruptura con el orden colonial; sin embargo, posteriormente, se configuró como funcional para la constitución del nuevo orden dominante, tanto interno como externo, en que cayeron las nuevas repúblicas, sentando las bases para el desarrollo de la burguesía y el surgimiento de un capitalismo dependiente, bajo la particular presión del comercio inglés que impuso la tesis del librecambismo, con 
el propósito de transformar las recién descolonizadas economías iberoamericanas en complemento de su propia economía.

\subsection{Liberalismo libertario}

En los procesos independentistas, el liberalismo estuvo asociado principalmente a la ruptura con los lazos políticos y económicos con la península ibérica. Para los criollos, la libertad era sinónimo de independencia.

Este liberalismo es el resultante de las vertientes ilustradas y románticas que fluían en los pensadores y libertadores de la época, las cuales junto con el ejemplo dado por las colonias inglesas de Norteamérica y, posteriormente, el cuestionamiento que de la monarquía representó la Revolución Francesa, así como los principios contenidos en la Declaración de los Derechos del Hombre y del Ciudadano, contribuyeron a formar un pensamiento liberal hispanoamericano que, aunado al vasallaje político y la discriminación entre peninsulares y americanos, conduciría a los movimientos independentistas y a la adopción de la República como modelo de organización socio-político (Bohórquez, 66).

\subsection{Liberalismo de orden}

Es el resultado de las influencias del espiritualismo racionalista y del positivismo. Tuvo lugar durante la segunda mitad del siglo XIX.

Desde esta perspectiva, el liberalismo aspira a poner orden en las nuevas Repúblicas y buscar el progreso de sus economías.

Los efectos que las políticas liberales de esta etapa tuvieron en las comunidades y pueblos indígenas, alteró los vestigios de sus estructuras sociales y culturales (Bragoni, 101). El mundo agrario burgués propugnará por la eliminación de las formas comunales y ejidales de la propiedad de la tierra.

Si bien en un principio, el liberalismo exhibe una unidad en la lucha contra los privilegios de tipo feudal del orden colonial, con lo que adoptó un cierto perfil radical; luego pasó a ser fundamentalmente conservador del nuevo sistema de privilegios propio de la modernidad capitalista.

De ahí que si bien se asocia al conservadurismo como la expresión política de los sectores sociales dominantes durante la historia colonial y al liberalismo como la fuerza democrática, lo cierto es que en el desarro- 
llo de América Latina se advierten, no sólo enfrentamientos entre estas fuerzas, sino también frecuentes alianzas e interacciones doctrinarias o fusiones entre ellos, que dará lugar a formas propias de liberalismo, no sin padecer de contradicciones y vaciamientos de sus postulados fundamentales.

\section{Crisis del liberalismo}

Durante toda su historia, el liberalismo ha tenido que enfrentarse a distintas ideologías que, de alguna manera u otra, se han expresado como alternativas al mismo y que han provocado sus grandes crisis como corriente de pensamiento en la región. Entre estas reacciones al liberalismo, se pueden mencionar: el conservadurismo, la tensión entre centralismo político e individualismo socioeconómico, las ideas liberales sobre la educación, la influencia del positivismo y la filosofía de la liberación.

\subsection{Conservadurismo}

El pensamiento conservador fue la expresión social dominante durante la larga historia colonial. El conservadurismo buscó y encontró en la independencia la ocasión propicia para optimizar sus privilegios y asegurarlos.

Por su parte, el liberalismo criticó de los conservadores su corporativismo tanto militar como eclesiástico, los privilegios de una sociedad fuertemente jerarquizada y el paternalismo en la conducción política.

Al triunfar el movimiento independentista, encabezado por los liberales, la reacción del conservadurismo no se hizo esperar, a fin de mantener o restaurar los elementos centrales del antiguo régimen.

Como resultado de estos conflictos, aparecen nuevas expresiones políticas, tales como el liberalismo conservador y el conservadurismo liberal. En consecuencia, el criterio diferenciador entre unos y otros, se encuentra más bien en sus actitudes prácticas, ya sea en su apertura hacia la modernidad y el progreso, por un lado, o en la conservación de tradiciones y situaciones procedentes del mundo colonial, por el otro.

De igual forma, con la Independencia surge una nueva clase dominante, integrada por liberales y conservadores, quienes compartían y alternaban en el poder, como resultados de alianzas y acuerdos. 


\begin{tabular}{|c|c|}
\hline LIBERALISMO & CONSERVADURISMO \\
\hline $\begin{array}{l}\text { - Estaba representado por sectores } \\
\text { sociales emergentes: burguesía agrícola, } \\
\text { bajo clero, mandos medios y bajos del } \\
\text { ejército. }\end{array}$ & $\begin{array}{l}\text { - Estaba representado por la tradicional } \\
\text { aristocracia terrateniente, el alto clero y las } \\
\text { altas jerarquías del ejército }\end{array}$ \\
\hline $\begin{array}{l}\text { - En general, optaban por formas fede- } \\
\text { rales de organizar territorialmente el } \\
\text { Estado. }\end{array}$ & $\begin{array}{l}\text { - Se inclinaban por el centralismo en el } \\
\text { ejercicio del poder político, como rema- } \\
\text { nente de la tradición monárquica. }\end{array}$ \\
\hline - Proponían la abolición de privilegios. & $\begin{array}{l}\text { - Proponían la consolidación o profun- } \\
\text { dización de los privilegios heredados de } \\
\text { la Colonia. }\end{array}$ \\
\hline $\begin{array}{l}\text { - Proponían la supremacía de la autoridad } \\
\text { civil y la secularización de la sociedad, } \\
\text { así como la separación entre Iglesia y } \\
\text { Estado, en sus vertientes más radicales } \\
\text { eran profundamente anticlericales. }\end{array}$ & $\begin{array}{l}\text { - Identificaban el poder de la Iglesia con } \\
\text { el poder del Estado. Eran de un acentuado } \\
\text { catolicismo. }\end{array}$ \\
\hline $\begin{array}{l}\text { - Se inclinaban por la ampliación y el } \\
\text { ejercicio de libertades. }\end{array}$ & $\begin{array}{l}\text { - Estaban por la restricción de libertades } \\
\text { para el pueblo. }\end{array}$ \\
\hline
\end{tabular}

En definitiva, la clásica diferenciación política post-independencia se resumirá en liberal republicano o conservador monárquico.

\subsection{Tensión entre centralismo político e individualismo socioeco- nómico}

La necesidad de reorganizar las formas políticas con posterioridad al derrumbe del sistema colonialista, mediante la creación de un Estado moderno, contrastaba con los principios de libertad en que se fundamentaron estos movimientos independentistas, lo cual supuso una nueva crisis para el liberalismo.

Por un lado, la noción del individuo ilustrado, dedicado a sus propios intereses, basado en la propiedad, entendida ésta como una extensión del derecho individual a la vida misma, se enfrentaba a la ideología unificadora y reformista, necesaria de un nuevo orden, así como a un sistema económico donde coexistían latifundistas, campesinos dependientes (esclavos, peones, indios), junto con una incipiente burguesía rural.

II Ilberallsmo hispanoamericano en el siglo XIX 
Por tanto, las élites terminaron aferrándose a la formalidad de una filosofía liberal, al mismo tiempo que se configuraban nuevas formas de dominación política. Para estos liberales, la cuestión se reducía a eliminar los privilegios legales y jurídicos del orden colonial, pero no apostaban verdaderamente por una ética del trabajo al estilo de la burguesía rural francesa posrevolucionaria o al pequeño propietario agrícola de los Estados Unidos (Bethel, 13).

Entre la variopinta modalidad política que adoptó el liberalismo, presionado por la necesidad de orden, se puede destacar la actitud del mismo Bolívar que en algún momento llegó a proponer - fundado en el planteamiento de Montesquieu, según el cual las leyes deben ser propias para el pueblo que se hacen- un gobierno representativo, pero en el cual "el Senado en lugar de ser electivo fuese hereditario" (Gómez).

De la misma forma, José de San Martín en Argentina, apoyaba la creación de una monarquía liberal como forma de mantener la paz y gobernar. Por su parte, Bernardo de Monteagudo, propondrá en 1812 el nombramiento de un dictador que responda de la libertad del pueblo, obrando con plenitud de poder según lo exijan las circunstancias (Gomez).

Esta debilidad que condujo más adelante al absolutismo partidario, fue percibida y descrita con enorme madurez por el chileno Francisco Bilbao, cuando advierte: "Los pelucones, los conservadores, los rojos, los liberales, los demócratas, los unitarios, los federales, todos han acariciado la dictadura. Con la mejor intención, se dicen íntimamente los partidos: 'la dictadura para hacer el bien'. Es decir: el despotismo para afianzar la libertad. iTerrible y lógica contradicción! El catolicismo da la corriente despótica. La república la corriente liberal. Y ambas corrientes se encuentran en la monstruosa consecuencia que se llama: 'la dictadura para fundar la libertad'” (Zea, V).

Esta oscura herencia liberal, la cual en lugar de estimular el liberalismo democrático, promovió los antiguos resortes que habían permitido en el pasado el despotismo, se describe en palabras de Zea como: "La manía de gobernar, por una parte, $y$, por la otra, la indolencia real o supuesta del pueblo para mantener sus derechos políticos, la supuesta incapacidad de éste, condujeron a los partidos al establecimiento gradual de un nuevo despotismo, de una centralización monstruosa. Frente al desorden, frente a la anarquía que siguió a la independencia política, se estableció una nueva unidad, pero despótica” (Zea, 113). 


\subsection{La propuesta por la educación}

Una nueva generación de liberales, conscientes de las crisis y de las consecuencias políticas que esta filosofía produjo en el ejercicio de las libertades, adoptó el liberalismo no sólo como bandera política, sino como instrumento para superar la visión idealista de los libertadores y transformar al ser americano mediante la educación, para lo cual reconocen la necesidad de adaptar estas ideas a la realidad americana (Zea, 129).

A juicio de estos pensadores, la causa del fracaso liberal radicó en la falta de visión o de oportunidades de los libertadores por enfrentar el principal problema de la educación del pueblo, prefiriendo más el éxito político inmediato.

En otras palabras, los libertadores no hicieron otra cosa que ofrecer la libertad, pero no los medios para disfrutarla (Zea, V).

\subsection{Positivismo}

El positivismo aparece en Hispanoamérica frente a la necesidad del organismo social por instaurar un orden y progreso. Aunque el término "positivismo" aparece ligado a la historia de este continente, lo cierto es que como denominación se atribuye a la serie de ideas filosóficas y sociales que proclamaban el triunfo de la ciencia en América Latina. Algunos autores cuestionan el poco rigor con el que se aplicó este término en la región (Bethel, 3 y 14).

Ahora bien, en sus sentido filosófico, el positivismo es una teoría del conocimiento, según la cual el método científico es el único medio de conocer que tiene el ser humano. Sus elementos de análisis son la observación y la experimentación, así como el rechazo de toda forma de conocimiento apriorístico y la búsqueda de leyes o relaciones en todos los fenómenos, incluidos los sociales.

Como teoría del conocimiento, no es una filosofía nueva. Su innovación radica en la formulación sistemática y en el propio término "positivismo", acuñado por Auguste Comte en sus Cursos de filosofía positiva (1830-1842).

En lo social, el positivismo sostenía que la sociedad era un organismo y no una mera suma de individuos y que el único método para estudiarla es la historia (Bethel, 14). 
En Hispanoamérica, la principal influencia del positivismo se dio en la reforma de la educación superior, por lo que la tradicional orientación humanística e idealista, latinista y filosófica, se convirtió en un nuevo campo de batalla ideológico entre tradicionalistas y positivistas, quienes proponían una formación técnica y de estudios utilitarios especializados.

Por otra parte, aunque el positivismo no era explícitamente una teoría política, lo cierto es que contribuyó a que se formulara el concepto de política científica, bajo la noción de que ésta era una ciencia experimental basada en hechos, por lo cual las ideas abstractas y fórmulas jurídicas como las del liberalismo, lo único que habían hecho es provocar revoluciones y desordenes. En cambio, los positivistas proponían cambios moderados, mediante reformas.

Desde esta perspectiva, la política científica tenía una relación ambivalente con el liberalismo, el cual dentro de la formulación de Comte, formaban parte del estado metafísico.

Para los liberales, la noción de política científica era asociada al autoritarismo y tecnocracia; en cambio los positivistas consideraban que la libertad era un logro del pasado, siendo el orden y el progreso la tarea para el futuro (Bethel, 19).

Con la llegada del positivismo, las doctrinas liberales y las formulas constitucionales fueron calificadas de metafísica (Bethel, 37).

En todo caso, la filosofía americana del Siglo XIX está marcada por el signo del positivismo, en vista de la necesidad de orden y progreso que se impone en los países, por lo que incluso algunos autores sostienen que existía en los hispanoamericanos una cierta predisposición al positivismo, dado su afán de modernidad, que acompaña a la Independencia y, más tarde, a todo el liberalismo (Villegas, 9-10).

El influjo del positivismo en los pensadores liberales es posible explicarlo por la necesidad de superar la escolástica como filosofía educativa y adoptar una filosofía basada en la ciencia que propiciara una mentalidad progresista (Vargas), por cuanto se cuestionaba a los filósofos coloniales, por no haber traído nada nuevo a estas tierras, sino más bien limitarse "a repetir las especulaciones de su tiempo, con un fin práctico, inmediato, religioso o político" (João Cruz Costa, citado por Villegas, 11). La escolástica, principal filosofía durante la Colonia, no 
era un movimiento creador sino puramente apologético para justificar los intereses de la metrópoli, desde una particular cosmovisión de poder (Villegas, 35).

Sin embargo, el positivismo hará lo mismo con la oligarquía que aspiraba a constituirse en la burguesía dominante, por lo que es impropio considerar al positivismo como una sola filosofía en este continente, cuando en realidad respondía a los distintos intereses de cada país. En común, tenían únicamente su rechazo a la escolástica y al principio de autoridad que ésta implicaba.

El positivismo hispanoamericano tuvo ciertas características, entre las cuales destaca su rechazo pleno a una cosmovisión en que el concepto de Dios era el centro de la misma (rechazo de la escolástica). En su lugar, los positivistas proponen la idea de la naturaleza. Así, llegarán a afirmar que "no hay Dios, los seres de la naturaleza se sostienen por sí mismos” (Ignacio Ramírez, citado por Villegas. 13).

Como puede notarse existió una fuerte fricción entre el liberalismo y positivismo, particularmente fundada en su concepción de la sociedad, pues "el liberalismo sostenía un individualismo, la separación de poderes, el federalismo, la autonomía municipal, el constitucionalismo y el Estado laico. Stuart Mill además abogaba por una combinación entre la lógica del mercado y la democracia que compensara las desigualdades producidas por la primera" (Vargas). Por su parte, el positivismo - aun guardando la distancia entre sus distintas variantes- se opone al derecho natural y al individualismo, considera que en la sociedad debe haber un orden y progreso, a menudo considerado éste como de forma determinista.

Korn advertía que el concepto mecanicista de progreso que asume el positivismo, suprime la libertad y, por tanto, toda ética (Citado por Villegas, 39). A raíz de estas diferencias, se derivó un problema de orden práctico: la conciliación entre positivismo y liberalismo.

Sin embargo, existían antecedentes históricos que lo dificultaban. Para el caso, Comte había criticado al liberalismo por haber hecho posible la revolución francesa y destruido el orden medieval. Para el fundador del positivismo, el progreso no podía obtenerse por medio de la libertad anárquica, sino sólo a través de una paz ordenada.

Por su parte, esta noción de "paz ordenada" propició el surgimiento de las dictaduras o gobiernos despóticos en Hispanoamérica, amparados 
por las necesidades de progreso y organización social de los nuevos Estados independientes. Así, en México el positivismo funge como justificador de la dictadura de Porfirio Díaz.

Para los liberales, el problema de la libertad a la luz del positivismo, hacía imposible cualquier coincidencia entre ambas filosofía. Así, para el positivismo, la libertad no es la facultad de hacer o querer sin sujeción a ninguna ley, pues esto sería inmoral y absurdo, dado que hace imposible todo orden; se trata más bien de someterse con entera plenitud a las leyes que determinan a los seres humanos, tal como ocurre con las leyes de la naturaleza... la plena sujeción a las leyes respectivas caracteriza, allí como en todas partes, la verdadera libertad. (Gabino Barreda, citado por Villegas 15). La concepción anterior impidió a algunos liberales mantenerse dentro del positivismo.

\subsection{Filosofía de la liberación}

La permanencia de repúblicas oligárquicas desde fines del siglo XIX y a lo largo del siglo XX, el profundo malestar como resultado de las promesas incumplidas del liberalismo y sus ideales de paz, progreso y prosperidad, significó el quiebre de las ilusiones del liberalismo clásico, supuso el resurgimiento de otras ideologías alternas, tales como: el anarquismo, el liberalismo social, el socialcristianismo, el comunismo, el fascismo y los nacionalismos, así como un profundo pesimismo sobre el ser humano (Vergara).

Con la filosofía de la liberación se constata que "el camino de llegar a la justicia por la libertad (liberalismo) ha tenido buenos resultados para los más fuertes, como individuos o como pueblos, en un determinado momento, pero ha dejado sin libertad (liberación) a la mayoría de la humanidad" (Galiana).

\section{Conclusión}

En términos generales, una de las características del liberalismo latinoamericano es su aplicación a sociedades fuertemente estratificadas, social y racialmente, así como a economías no desarrolladas y sociedades con fuerte arraigo en la tradición de una autoridad estatal centralizada, a la vez con mucha resistencia y hostilidad, por parte del conservadurismo.

Asimismo, el liberalismo americano difiere del europeo, por cuanto en el Viejo Continente, era una expresión de una clase social en ascenso;

\section{0}


en cambio en el Nuevo Mundo fue un repertorio doctrinario que sectores ilustrados minoritarios utilizaron para fundamentar la revolución independentista y proyectar su propio ascenso y consolidar su hegemonía. Esto se refleja en la conocida frase de Cecilio del Valle: "proclamemos la independencia, antes que el propio pueblo la declare".

El liberalismo, entonces, estuvo condicionado por complejas coyunturas, que en algunos casos modificó sus postulados fundamentales. Por ello, la tensión final al interior del liberalismo se puede plantear en términos de liberalismo-oligárquico versus liberalismo-democrático.

Martí registró las limitaciones del proyecto liberal, al constatar que sus reformas no habían sido capaces de superar las condiciones que imponía el orden conservador, y la consolidación de la oligarquía terrateniente, una economía dependiente primario- exportadora y el predominio de la república oligárquica liberal sobre el proyecto democrático liberal.

Sin embargo, el liberalismo aportó los elementos básicos para la configuración de los modernos Estados hispanoamericanos, marcados por el respeto a los derechos individuales, el republicanismo y la sujeción a la ley. Queda aún por hacer y escribir la historia de la filosofía de Hispanoamérica que responda a los verdaderos intereses de las grandes mayorías mantenidas en exclusión hasta nuestros días.

\section{BiBLIOGRAFÍA}

Acosta, Yamandú. "El liberalismo. Las ideologías constituyentes. El conflicto entre liberales y conservadores". En El pensamiento social y político iberoamericano del siglo $X X$. Ed. Arturo Andrés Roig. Trotta. Madrid, 2000.

Bethell, Leslie (ed.). Historia de América Latina. Vol. 8. Editorial Crítica. Barcelona, 1991.

Beuchot, Mauricio. "Filósofos bumanistas novobispanos". En AAVV, Filosofía iberoamericana en la época del encuentro. Trotta. Madrid, 1992.

Bohórquez, Carmen L. "La tradición republicana. Desde los planes monárquicos hasta la consolidación del ideal y la práctica republicanas en Iberoamérica". En El pensamiento social y político iberoamericano del siglo XX. Ed. Arturo Andrés Roig. Trotta. Madrid, 2000. 
Bragoni, Beatriz. "La formación de la conciencia burguesa en Iberoamérica durante el siglo XIX". En El Pensamiento social y político iberoamericano del siglo $X X$. Ed. Arturo Andrés Roig. Trotta. Madrid, 2000.

Fernández Nadal, Estela María. "El proyecto de unidad continental en el siglo XIX. Realidad y utopía”.- En El Pensamiento social y politico iberoamericano del siglo $X X$. Ed. Arturo Andrés Roig. Trotta. Madrid, 2000.

Ferrer Muñoz, Manuel. "Presencia de doctrinas constitucionales extranjeras en el primer liberalismo mexicano" [en línea]. Biblioteca Jurídica Virtual. Instituto de Investigaciones Jurídicas de la UNAM. 2001-2004. http://www.bibliojuridica.org/libros/2/804/3.pdf

Galiana, José Mora. "Para leer a Ignacio Ellacuría". [en línea]. Proyecto Ensayo Hispánico. 1997-2003. Gómez-Martínez, José Luis (Ed.). http:// www.ensayistas.org/filosofos/spain/ellacuria/critica/mora-g4.htm. [Consulta: 24 de noviembre de 2004].

Gómez-Martínez, José Luis. "Pensamiento iberoamericano del siglo $X I X$ ”. [en línea]. Proyecto Ensayo Hispánico. 1997-2003. Gómez-Martínez, José Luis (Ed.). http://www.ensayistas.org/critica/generales/gomez3.htm [Consulta: 24 de noviembre de 2004].

Pérez Fernández, Isacio. "Bartolomé de las Casas". En AAVV, Filosofía iberoamericana en la época del encuentro. Trotta. Madrid, 1992.

Santana Castillo, Joaquín. "Identidad cultural de un continente: Iberoamérica y la América Sajona. Desde la doctrina Monroe hasta la guerra de Cuba". En El pensamiento social y político iberoamericano del siglo XX. Ed. Arturo Andrés Roig. Trotta. Madrid, 2000.

Serrano Caldera, Alejandro. "Las últimas etapas de la Ilustración y el despertar $y$ desarrollo del romanticismo". En El pensamiento social y político iberoamericano del siglo $X X$. Ed. Arturo Andrés Roig. Trotta. Madrid, 2000.

Vargas Lozano, Gabriel. "Esbozo bistórico de la filosofía mexicana del Siglo XX" [en línea]. Proyecto Ensayo Hispánico. 1997-2003. GómezMartínez, José Luis (Ed.). http://www.ensayistas.org/critica/mexico/ vargas/. [Consulta: 24 de noviembre de 2004].

Vergara Estévez, Jorge. "Cultura y mestizaje en América Latina. Una crítica a la tesis de la identidad cultural mestiza". [en línea]. Proyecto 
Ensayo Hispánico. 1997-2003. Gómez-Martínez, José Luis (Ed.). http:// www.ensayistas.org/filosofos/argentina/roig/homenaje/vergara.htm [Consulta: 24 de noviembre de 2004].

Villegas, Aberlardo. "Panorama de la filosofía iberoamericana actual". Editorial Universitaria de Buenos Aires. Argentina, 1963.

Yturbe, Corina de. "Multiculturalismo y derechos". [en línea]. Biblioteca Jurídica Virtual. Instituto de Investigaciones Jurídicas de la UNAM. 2001-2004. http://www.bibliojuridica.org/libros/1/490/4.pdf. [Consulta: 23 de noviembre de 2004].

Zea, Leopoldo. "El pensamiento latinoamericano". Editorial Ariel. $3^{\mathrm{a}}$. Edición. México, 1976.

Zea, Leopoldo. "El pensamiento latinoamericano". Proyecto Ensayo Hispánico. 1997-2003. Gómez-Martínez, José Luis (Ed.). http://www. ensayistas.org/filosofos/mexico/zea/pla/ [Consulta: 24 de noviembre de 2004]. 